\title{
MORAL ECONOMIES OF CONSUMPTION
}

Abstract: The aim of this paper is two-fold; first, to bring together debates about enduring normative concerns surrounding the morality of consumption with more recent concerns about the ways specific moralities are constituted in and through markets. The second aim is to develop the concept of 'moral economy' and call for an approach to its study attentive to how moralities of consumption develop through interactions between instituted systems of provision, forms of state regulation, customs within communities and the everyday reflections of consumers about the things that matter to them. As consumers are increasingly asked to factor environmental and fair labour concerns into their purchase and post-purchase habits, there is a real need to understand how moralities of consumption are both formatted through institutional frameworks and shaped everyday by actors from within. After developing a framework for the study of moral economies, this paper explores in depth the experiences of one couple in relation to the cessation of a cardboard recycling collection in Shropshire (England) to show why a multi-level perspective is needed to appreciate the place of morality within the market.

Keywords: Consumption; Consumer critique; Economic Sociology; Moral Economy; Morality; Recycling

The aim of this paper is two-fold; first, to bring together debates about enduring normative concerns surrounding the morality of consumption with more recent concerns about the ways specific moralities are constituted in and through markets. The second aim is to 
develop the concept of 'moral economy' and call for an approach to its study attentive to how moralities of consumption develop through interactions between instituted systems of provision, forms of state regulation, customs within communities and the everyday reflections of consumers about the things that matter to them. As consumers are increasingly asked to factor environmental and fair labour concerns into their purchase and post-purchase habits, there is a real need to understand how moralities of consumption are both formatted through institutional frameworks and shaped everyday by actors from within.

The term 'moral economy' is often attributed to historian E.P. Thompson (1971) whose essay on food riots in eighteenth-century England explored how communities drew upon shared norms and customs of the older paternalist order to justify their protest at unfair grain prices. Thompson's 'moral economy' conceptualised capitalist markets and moralities as incompatible, rehearsing an enduring analytical separation between the worlds of rational economic activity and relations of sentiment and solidarity, termed by Zelizer (2011) as the 'separate spheres and hostile worlds doctrine'. Rejection of this dualism has motivated a body of work within economic sociology that recognises the importance of interpersonal relations and moral ties, institutional frameworks and material devices within the construction of all markets (Callon, 1998; Fourcade and Healy, 2007; Harvey, 2007; Sayer, 2000; Zelizer, 2011). These more relational approaches draw attention to the coconstitution of markets and moralities but generally refrain from commenting on the virtue 
of these markets. On the other hand, academic and societal critiques of consumption explicitly question the virtue of current patterns of consumption within capitalist markets (King, 2008; Klein, 2000; Schor et al., 2010; Soper, 2008; Szasz, 2009). Such critiques have highlighted the environmental and social consequences of unsustainable consumption. Growing ethical consumer movements, like Fairtrade, green living, and community supported agriculture, are understood as a response to such critiques and scholars have explored how such moralities of consumption are promoted and practiced (Ariztía et al., 2014; Barnett et al., 2011; Brown, 2013; Pellandini-Simányi, 2014; Varul, 2009; Wheeler, 2012b, 2014; Wheeler and Glucksmann, 2015). This paper brings together those more descriptive accounts of the ways moralities are performed and enacted within markets (characteristic of new economic sociology) with the enduring normative critiques of consumer capitalism.

It is recognised such an approach is full of contradictions that runs the danger of replicating the 'separate spheres/hostile worlds' fallacy. It is for this reason the second aim of this paper is to develop an analytical framework for exploring how moralities of consumption are constituted at the micro, meso and macro levels, with the hope this multilevel perspective can address persistent theoretical questions about the place of morality within markets. Viewing certain aspects of consumer capitalism as corrosive of morality and destructive of society demands academic enquiry takes a moral stance to explore the 'dark side' of capitalism. Zelizer's (2011) review of the development of economic sociology 
highlights few scholars have spent energy critically questioning the institutions they study. It would be unfair to claim economic sociologists are alone in this as social scientists more generally have shied away from engaging with normative questions about the nature of the social worlds they study and 'why things matter to people' (Sayer, 2011). Demands for objectivity and value-freedom have opened up those who do offer normative critiques of consumption to the challenge that their middle-class material anxieties are producing moralistic (or indeed condescending and racist) accounts out of touch with the everyday realities of poverty and the need for more consumption across the globe (Miller, 2001; Schor et al., 2010). Such attacks reveal what is at stake in debates about the morality of consumption and the need for a framework that brings together different layers of analysis to better understand the possibilities for creating more ethical consumer practices.

This paper takes as its starting point a theoretical framework developed to understand the moral economy of work and employment (Bolton and Laaser, 2013) largely informed by three key thinkers (Polanyi, 1944, 1957, Sayer, 2005, 2011; Thompson, 1971). I argue this framework can be extended to the field of consumption and in so doing reconcile the new economic sociology's insistence that markets are moral and moralizing projects with critical accounts of the morality of consumer culture without replicating the separate spheres fallacy. This is important because academics should adopt a critical stance to explore the causes and consequences of inequality and injustice within consumer capitalism to both the environment and society, but this critique must be grounded in the context of how markets 
are made and incessantly negotiated through moral ideas, institutions and practices embedded at the micro, meso and macro levels of the economy. This framework achieves this aim through both highlighting the performative role of critical discourse about the morality of the market at the meso-level of the framework, as well as bringing the Polanyian perspective of 'institutional embeddedness' (Bandelj, 2012; Harvey, 2007; Krippner, 2001) into conversation with the new economic sociology. This paper outlines the distinctive approach to moral economy proposed before using an illustrative example from research into household recycling to highlight why such an approach is needed.

\section{MORAL ECONOMIES OF CONSUMPTION}

'Moral economy' has a long heritage and has been employed to account for the rise of many contemporary and historical ethical consumer movements (Fridell, 2006; Goodman, 2004; Trentmann, 2007). Yet this concept is insufficiently interrogated and comes to stand for any attempt to 'moralize' the inherently immoral economic system of capitalism (see Jackson et al., 2009 for a notable exception). This section demonstrates how diverse literatures can be brought together into an overarching analytical frame that challenges the assumption that morals and markets are incompatible.

A good starting place for thinking about the concept of moral economy is Sayer's definition as 'the study of the ways in which economic activities, in the broad sense, are influenced by moral-political norms and sentiments, and how conversely, those norms are 
comprised by economic forces' (Sayer, 2000: 80). Such a definition moves us away from the 'separate spheres' and instead forces us to view markets as neither an inherently civilising nor destructive entity but incessantly negotiated. The dualism between economy and culture has been an intransigent feature of much economic sociology, yet recent scholarship has challenged this (Bandelj, 2012; Fourcade and Healy, 2007; Harvey, 2007; Krippner, 2001; Zelizer, 2011). Markets are not just viewed as embedded within culture (as Granovetter's (1985) thesis proclaims) but are understood as being produced through practices of human sense-making as 'explicitly moral projects, saturated with normativity' (Fourcade and Healy, 2007: 299-300). Zelizer's (2011) various contributions to the field stand out in this regard with her insistence that markets are continually negotiated social projects making it impossible for moral boundaries to be understood outside of the market relations that constitute them in practice.

Accepting that morals and markets are co-constituted follows another strong tenet within economic sociology on performativity (Callon, 1998; Callon et al., 2007). Callon and colleagues have drawn attention to how the discipline of economics - with its calculative agencies and actors operating in a free market - has had a powerful influence on both popular understandings of the economy (as a separate world) and upon the material and discursive devices that make up the market. Although commenting upon the virtue of the market has not been a key feature of this work - indeed their approach has been described as agnostic (Mcfall, 2009) - the performative turn opens the possibility of bringing 
longstanding normative critiques of consumption into conversation with these thick descriptive accounts of the market. For if economics as a discipline can shape the market it describes so too can the various societal and academic critiques of consumption (Klein, 2000; Schor et al., 2010; Simms et al., 2009; Soper, 2008). Indeed Schor's (2010) contribution to this journal makes a similar point when she calls for social scientists to engage with the moral sphere as an 'analytic imperative' because debates about consumerism are transforming mainstream markets from a values-driven perspective.

Bringing these two sets of literatures together represents both a challenge and much promise given the different emphasis each takes on adopting a moral stance on the political economy of capitalism. Turning to a framework developed in the field of work and employment is useful to connect the analysis of 'political economy, the (a)morality of markets under liberal capitalism and the lived reality of the everyday work situation [or in our case consumption practices] for a range of people' (Bolton and Laaser, 2013: 511). The moral economy framework developed by Bolton and Laaser (2013) utilises three strands of the study of moral economy from the writings of Karl Polanyi (1944, 1957), E.P. Thompson (1971), and Andrew Sayer (2005, 2011). I argue their framework can be extended to the field of consumption by bringing together writings from the fields of economic sociology on the morality and performativity of markets with traditions of consumer critique. My multi-level framework locates three layers of analysis of morality within the market - state regulation, collective customs and lay normativities - and argues 
interactions between these elements are situated within a broader instituted system of provision.

The framework begins with Polanyi's $(1944 ; 1957)$ (then groundbreaking) thesis that refutes the separatist position between market and society. Polanyi challenged the idea of the selfregulating market and instead argued all economies are underpinned by social, political and moral values which enable them to function. Polanyi's ideas have been central to the development of economic sociology, particularly his notion of market embeddedness. Polanyi used this concept in different ways in The Great Transformation (1944) and his essay ‘The Economy as Instituted Process' (1957). Bandelj (2012) makes a useful distinction between them - 'embeddedness as a variable' and 'institutional embeddedness' - and both are crucial for the moral economy framework. Thinking of embeddedness as a variable is compatible with Polanyi's earlier writing which explored how the market economy pursues self-regulation through market prices. He argued the fictitious commodities of 'land, labour and money' cannot be solely directed by the market mechanism without 'the demolition of society' (Polanyi, 1944: 76). Therefore, society protects itself through a 'double movement' which comprises 'a network of measures and policies... integrated into powerful institutions to check the action of the market' (ibid.: 79). Polanyi emphasised the role of the state in managing the supply and demand of these fictitious commodities and stepping in to protect people and the environment from the logic of capital (Block and Polanyi, 2003). For the moral economy framework proposed, analytically separating out the state is 
useful, given its role in upholding moral principles and distributing benefits and sanctions based on law and citizenship.

Nevertheless, viewing the state as a necessary regulator of the economy might foster a vision of some markets as embedded and others not (particularly the self-regulating market) - embeddedness becomes a variable. So Bandelj (2012) characterised Polanyi's later work through the concept of 'institutional embeddedness' considering his claim 'the human economy... is embedded and enmeshed in institutions, economic and noneconomic' (Polanyi, 1957: 250). This always-embedded understanding of the economy must play a critical role in our revised moral economy framework if we are to move beyond the separate spheres. It must acknowledge the market as 'coterminous with the groundwork of society itself (Krippner, 2001: 801), chiming with those thick descriptive accounts that see all markets as moral and moralising projects. What then needs to be added is how the normative critique of consumer culture becomes enmeshed with economic and noneconomic institutions.

To do this, Krippner's (2001: 800) assertion concepts 'carry with them the traces of prior junctures $[\ldots]$ in the history of ideas' is instructive. Most accounts of 'moral economy' (Bolton and Laaser, 2013; Fridell, 2006; Jackson et al., 2009; Sayer, 2000) draw on writings of E.P. Thompson (1971) whose study of food riots is used to exemplify how free markets are divested of moral sentiment and solidarity. Thompson highlights the role of collective 
movements who act without state intervention to resist processes of marketisation and together oppose unfair or destructive economic practices, defending their 'traditional rights and customs'. This influential discourse has historically shaped academic understandings of the respective places of morality and the market within moral economy perspectives. Being aware of the discursive power of concepts and ideas encourages us to reflect on the performativity of not only academic knowledge claims and normative critiques of consumer culture, but also collective mobilisations by social movements and sociohistorical 'customs' that carry moral evaluations of communities. In their review of market morality, Fourcade and Healy (2007: 304) argue we have witnessed markets being 'actively moralized by the deployment of practical techniques', and these 'practical dispositifs [...] work to bring markets in line with moral ideals'. Using performativity, academic and societal critiques of the morality of consumption can be integrated into our moral economy framework. Debates about whether society consumes too much (King, 2008; Simms et al., 2009), whether we ought to be pursuing non-materialist pursuits (Soper, 2008), and whether practices of consumption negatively impact upon humanity and environment (Girling, 2005; Klein, 2000; Szasz, 2009) join the political landscape at the level of 'collective customs' alongside popular campaigns to promote particular moralities of consumption within corporate, civil society and community organisations. Different communities actively mobilise 'collective customs' and critical discourses about the morality of consumer culture which in turn shapes and 'enmeshes' the normative critique within economic institutions. These different voices may articulate different 'orders of 
worth' from the logic of the market, civic or domestic spheres each using different modes of evaluation (Boltanski and Thévenot, 1999). But what is important is to explore how these modes of evaluation are mobilised through practices, discourses and institutional configurations which then shape the market in their image.

So far the discussion has focused on the macro and meso levels of the framework, but it is crucial not to lose sight of possibilities for moral agency operating at the micro-level. Public discourses offer useful 'rationales' that guide how people think about their practices, but these same discourses are 'open to different interpretations and uses... [and] contain inconsistencies and contradictions making them open to challenge from within' (Sayer, 2005: 7). It is this recognition of the plurality of people pursuing 'different and often contradictory goals in life, dovetailing commitments and concern about things that matter to them' (Bolton and Laaser, 2013: 515) that provides the foundation of the final layer of the moral economy framework. Humans are deeply 'evaluative ethical beings' capable of embracing or rejecting community norms, offering reasons for participating in economic practices or not. Informed by Sayer's $(2005,2011)$ extensive work on the need for social scientists to take everyday morality seriously, the final layer seeks to bridge the gap between institutional/community norms and people's everyday reflective capacities. Here consumers' lay normativities - questions about 'what is of value, how to live, what is worth striving for and what is not' (Sayer, 2005: 6) - take centre stage, revealing the diversity and complexity of social and moral life. Using this lens, we can learn how everyday lay 
normativities are shaped within and against broader instituted systems of provision and cultural repertoires, recognising the interdependent relationship between these elements that together constitute distinct moral economies of consumption. Listening to individuals' lay normativities in the context of institutional and cultural settings is crucial if we want to learn why people choose to consume as they do and the values important to them.

\section{THE MORAL ECONOMY FRAMEWORK}

I am proposing three distinct layers of analysis for exploring moral economies of consumption. These are, 1) state regulation of the economy, 2) the collective customs and critical discourse through which different groups in society actively moralise the market, and 3) the lay normativities of consumers. At the first layer, state regulation is acknowledged as a powerful force that creates, promotes and sanctions economic processes that are harmful/beneficial to humans and environment. The impetus for these actions may be found in the second layer of the framework as social movements, community activists, businesses, public figures and academic critiques actively challenge, defend and appropriate different understandings of market morality which in turn has the potential to shape the market in line with their image of it. The third layer bridges the gap between state, institutional and community norms to call attention to lived experiences of diverse consumers going about their daily routines, reflecting upon the things that matter to them, and organising their consumption accordingly. 
Interactions and interdependencies between these three layers should be thought of as a dynamic relational complex configured through 4) a distinct 'instituted system of provision' (ISP) that represents the existing (but by no means fixed) organisation of the provision of commodities or groups of commodities within socio-historical settings. Drawing on Harvey's (2007) concept of 'instituted economic processes' and Fine and Leopold's (1993) 'systems of provision', the instituted system of provision represents the dynamic interrelations between economic processes (production, distribution, exchange and consumption) and how these are 'historically instituted in space and at different scales, local, global and regional' (Harvey, 2007: 177). Emplacing the three layers within an 'instituted system' allows the always-embedded nature of the economy (Bandelj, 2012) as a moral/moralising force to be maintained. The three layers of the framework can configure and shape the economic processes they relate to and indeed those economic processes can influence how institutions, communities and people enact morality within the market. There is a temporal dimension to the model because moral economies are never fixed but negotiated in the context of specific socio-historical contexts (Cohen, 2003; Trentmann, 2007).

A key feature of the framework is its dynamism, with each layer interacting and interdepending with the other. Each layer of analysis can be visualised as a moving object within the instituted system of provision which has the potential to connect or collide with each of the other levels, thus allowing for macro, meso and micro level moralities to shape 
one another. The ISP, although more rigid and less pliable, can be influenced by the three interacting layers of analysis. The locus of power shifts between the different layers, depending upon the type of moral economy we are dealing with and the scale we are focusing our analysis. Gaining insights into points of conflict, acceptance and negotiation between these layers can highlight potential levers for social change to motivate more sustainable consumer practices, being attentive to both structure and agency.

This framework offers a multi-level perspective that brings literature from economic sociology into conversation with normative critiques of consumer culture to analyse how specific moralities are constituted in and through markets. This is an important because debates about moral economy have for too long been polarised and need to be reconciled so that questions about the virtue of markets are brought into the concrete analysis of how markets are made in distinct socio-historical contexts. Whilst using similar building blocks to Bolton \& Laaser (2013), the framework proposed in this paper has been significantly extended so it can be applied to the field of consumption. The contributions of Polanyi (1944; 1957) have been clarified in the new framework so that on the one hand the normative view of the market as a potentially destructive force requiring the state to act as an agent of morality to protect humans from the logic of capital is maintained, whilst on the other Polanyi's insistence that all economies are embedded in institutional contexts offers the overarching frame for the different layers of the analytical scaffold to interact within. Central to this new framework is the introduction of performativity through which 
academic and societal critiques of consumer culture - so often predicated on the idea of separate spheres - actively shape the morality of the market. Thus, Thompson's (1971) 'collective customs' become the wide-ranging cacophony of different discourses mobilising different justificatory principles that are (or might be) enmeshed in the devices and practical techniques of economic institutions, which in turn inform understandings of possible forms of morality. Listening to the everyday lay normativities of consumers 'breathes life' into the framework as we learn how reflective actors negotiate and manage expectations placed upon them to consume responsibility for personal, societal and environmental causes.

\section{APPLYING THE FRAMEWORK}

Having outlined the theoretical bases for a new moral economy framework, it is necessary to show its practical application. Research on ethics and consumption is a growing area of academic interest in the context of the rise of ethical and sustainable consumer movements, like Fairtrade and green living. Much has been learnt about how these movements are regulated and institutionally configured within different societies (Ariztía et al., 2014; Boström and Klintman, 2006; Wheeler, 2012b; Wheeler and Glucksmann, 2015), how moralities are communicated to consumers through various marketing tactics (Wheeler, 2014), how different organisations and communities shape public debates around the moral imperatives for consumers and other actors to change their practices (Barnett et al., 2011; Varul, 2009; Wheeler, 2012a), and how consumers themselves understand and engage with 
ethical consumer practices (Evans, 2014; Gregson et al., 2007; Wheeler, 2012b). But it is rare to see all of these elements explored within a single study, or the implications of these varied findings brought together into an holistic framework. In this section, I explore in depth one incident that occurred during a wider research project into household recycling. ${ }^{1}$ I examine this incident in relation to the three layers of analysis to demonstrate the importance of taking a multi-level perspective to account for moral economies of ethical consumption. $^{2}$

\section{CARDBOARD RECYCLING IN SHROPSHIRE}

Ivy and Brian live in a council house in Shropshire (England) with their three children, who are all under 5 . The couple are unemployed; Brian having been previously homeless before moving in with Ivy. I visited them in 2012 to learn about their recycling routines. Brian is a keen recycler because he hates to see waste; he knows 'there's money in it'. Most of the packaging the family accrues can be recycled in the local authority recycling scheme which is collected from the kerbside on a fortnightly basis. Although Brian keeps hold of any metal or tins which he sells separately to a local scrap merchant for the 'kid's holiday fund'. But in recent months, the local recycling service had changed and was no longer accepting cardboard because new environmental legislation meant it could not be mixed with garden waste. Brian was quick to tell me how annoyed he was by the removal of the cardboard collection and how he now must burn his cardboard or dump it down the lane because the council will not collect it. Ivy had called the council to ask for a bigger bin to dispose of the 
cardboard as general waste and was told her family was not big enough to warrant a larger bin. She recounted 'they actually did expect us to go on the bus with the kids and the cardboard. I said are you going to refund the bus fare? I've got 3 kids and am on benefits, 'tough". The couple have joined together with a few neighbours who are having similar problems with the changed collection and are taking turns to burn their cardboard in their back gardens.

State regulation: Taking our first layer of analysis, the existence of a recycling scheme in Shropshire managed by the local government in partnership with a waste management firm provides the overarching context for the episode that unfolds. In response to national government and European Union targets to increase recycling, all local authorities are required to offer kerbside collections of consumer recyclable materials. The state has acted (albeit as a response to external pressures) to protect the environment from the damage caused through waste materials. To ensure this imperative is taken seriously, the state implemented a series of market devices, including a monetary tax on dumping waste in landfill and quotas/targets for landfill by 2020. These policies have influenced how collection services are organised as local authorities and companies search for an alternative to landfill. Unlike in parts of Europe where producer responsibility schemes are part of a closed-loop system, in England consumer packaging waste is open on the market for whoever wants to take the risk to sell it. In Shropshire (as in many other regions in England) that risk is shared between the local authority and a private waste management 
company. Waste management was one of the first public services to be privatised in the wake of neo-liberal restructuring in the 1970s. Following this trajectory, successive councils in Shropshire have partnered with private firms and in 2009, the council entered a 27 -year contract with Veolia. They knew they would be unable to meet Landfill trading allowance targets without the investment of a private firm to provide alternative infrastructures for disposal (incineration and composting facilities) as well as access to vehicle fleets and materials markets. Veolia and the council agreed the level of service provision offered across the county and the procurement of a separate paper, glass, tin and plastics and green waste and cardboard collection was established, alongside a fortnightly collection of general waste.

Then in 2011, following national concerns about levels of physical contaminants (such as glass, metals and plastics) in biowaste products deemed damaging to feedstock and environment, the government quango for waste, WRAP, and the Association for Organics Recycling made a change to the specification for organic compost under the PAS-100:2011 standard. Cardboard could no longer be composted alongside garden waste. Thus the market for organic compost (the end destination for Shropshire's combined garden and cardboard recycling scheme) was altered and Shropshire council removed the cardboard collection from their residents. 
When I visited the council recycling officer in 2012, he explained the decision to remove the recycling collection was carefully weighed against the economic viability of offering a new collection for cardboard alongside the paper collection. But this would have involved procuring at least 5 more vehicles through Veolia - a process that involved lengthy contract negotiations, changed collection days and access to a facility that could sort the materials for processing - as well as potentially damaging the profitability of their paper stream. Cardboard is a voluminous material but relative to the costs of disposing of it via landfill, it was not worth the extra investment. He concluded at that time:

on pure harsh, cold economics it probably doesn't stack up. Obviously, the environment side and the public satisfaction...I think it obviously stacks up on that side of things but you know councils are being told to be more business-like

Important to highlight here is how the context of austerity was shaping waste management and other public service provision. With councils told they needed to make cuts to public spending, difficult decisions about benefits and services needed to be made and the national waste policy agenda actively encouraged local authorities not to 'increase costs at a time when we are facing real challenges in reducing the deficit' (DEFRA, 2011: 2).

Focusing on the layer of state regulation, we see how moralities around the environment are used to construct economic policies to promote greater recycling levels within households in England. Market devices like taxes and quotas incentivise actions to protect the environment and are implemented into a system of provision marked by its part-public, 
part-private sector organisation, as well as established disposal mechanisms that rely on existing monitoring procedures. The transformation of PAS-100 standards disrupted this instituted system of provision, forcing different actors to evaluate the monetary costs of recycling against alternative 'orders of worth'. Civic and market-oriented values were negotiated in the context of limited economic resources, private provision and discourses of austerity. At this layer, we learn how environmental moralities are organised at the macro level through a network of policies, material infrastructures and market devices, and how this has transformed the local services offered to Ivy and Brian. But we cannot account for Brian and Ivy's annoyance/anger at the removal of the cardboard recycling service - for this we need to explore the second and third layers of the moral economy framework.

Collective customs: Growing levels of consumer waste and their impact on the environment and public purse feature prominently in public debates both at the national and local level. It is not uncommon to hear we are living in a throwaway society, with normative critiques levelled at the wastefulness of capitalism and the carelessness of consumers (Girling, 2005; Gregson et al., 2007; Packard, 1960; Simms et al., 2009). Environmental movements like Friends of the Earth (FOE) have been active in connecting sustainable waste management with environmental morality and care - indeed their briefing reports advocate the re-use and recycling of cardboard rather than its use within compost waste (FOE, 2004). Recycling cardboard is promoted as a 'good' thing to do by various institutions, including 
local authorities, campaign and community groups, retailers and companies. These different organisations promote and defend recycling as a worthy action, whether in terms of not wasting useful resources, protecting the environment or pride in one's community (e.g. not dropping litter).

Given the focus on the performative elements of market morality at this layer of the framework, it is first worth highlighting that the changes to the PAS-100: 2011 standards were made following consultation with environmental management organisations, waste companies and associations, existing environmental legislation and scientific reports. Concerns about levels of physical contaminants (plastics and metals) within compost products articulated by different organisations and experts provided the impetus for certification standards to be altered. Rather than morality towards the environment being external to the valuing of the product, critical discourses worked in tandem with state regulation to shape the moral economy for compost. The consequence for cardboard recycling in Shropshire only becomes apparent in the context of historic systems of waste management provision that collect this material alongside garden waste on a privatised basis.

Following the cessation of the cardboard collection in Shropshire, there was much dissatisfaction amongst the population because it was understood as a wasteful loss of a useful resource and a violation of norms of cleanliness. A petition was started to restore 
weekly rubbish collections, gaining over 1000 signatures, and local news reports highlighted the difficulties for those unable to get rid of their cardboard. Residents were upset that a service they felt entitled to as citizen-consumers (paid for through their council tax) was being removed without adequate provision for alternative forms of collection. Although the petition did not lead to a change in collection services at that time, it does show how people can together resist macro-level processes that go against their normative expectations. This public mood was soon taken forward when Transition Town Shrewsbury organised a community collection of cardboard at Christmas. The Transition movement is a grassroots community-led action group seeking to promote local solutions to climate change through self-sufficiency. The material collected during 'CardboardChristmas' by community groups and volunteers via collection stations and door-to-door visits was sold on to raise money for several local hospices and charities with the help of a local waste firm (Pink Recycling). One of the organisers described the event:

People came on foot, by bike and disability scooter; they pushed wheelbarrows and prams full of card; they brought cardboard in their cars from their friends and neighbours. The sun shone and there was a fantastic buz: created by volunteers who started the day as strangers and ended up as a close-knit team. (Transition Town Shrewsbury Website)

The event was such a success that Transition Shrewsbury partnered with several local organisations (Ludlow Agenda 21, Ludlow Pride of Place) to develop a community action guide to help others to organise community collections to keep cardboard out of landfill. A 
local councillor, Anthony Boddington, praised the 'worthy efforts' of these volunteers and social enterprises on his blog at the same time as he lamented the falling recycling rates in the county which he attributed to the privatisation of waste services. Whilst the council was unable to realise the value of cardboard within its inflexible private waste contract, these community groups showed how this material could be made to matter; both as a message to local governments that there was a will to recycle cardboard, as well as a gift to local charities for whom such economic contributions were not insubstantial. In short, their interventions created a new market for cardboard materials where none existed before.

Focusing on this layer of the framework, we see how various community, professional and expert voices have, in different ways, acted upon and transformed the moral economy of compost and cardboard recycling at the local and national level. Mobilised by different sets of knowledge to protect the environment and value materials, the markets for these two materials were actively moralised in ways that interacted with instituted systems of provision in distinct socio-historical contexts - the moral economy is differently configured in Shropshire relative to other parts of England. Communities within Shropshire challenged the state and private sector valuation of cardboard as not worthy of the effort and together shaped community norms, or collective customs, around alternative ways to value this material. 
Of course, not all consumers were concerned enough about the removal of the cardboard collection to join the 'Cardboard Christmas' campaign, but given altered collection services and reduced bin capacity, many were forced to change their daily waste practices which they did in accordance with the things that mattered to them.

Lay normativities: It would be easy to look at falling recycling rates and increases in flytipping in Shropshire as examples of careless consumers with little regard for the environment or other people. Yet by listening to consumer's everyday reflections on the handling of their waste, we learn how moral imperatives to recycle are negotiated with other everyday demands and life experiences that relate to ideas about what practices ought to be valued. Returning to Brian and Ivy's narrative, we will remember that the couple were recycling their cardboard before the change to the service. Brian was very keen on recycling; anything he can recycle, he does and his life ambition was to own a scrap-yard so he could turn waste into cash for his family. Brian's previous experience of being homeless has no doubt shaped the values he attaches to these materials as potential sources of income. He could not understand the removal of the cardboard collection; 'there's big money in recycling cardboard and they're throwing it away, putting it in landfill sites, how stupid is that!'

For Ivy, on the other hand, the removal of the cardboard collection raised different concerns. 
It's not cos I don't like it [recycling] but when you've got 3 kids it's just easier to

chuck it in the bin, can't be dealing with sorting out recycling, it's just another worry,

another thing to add to your week.

As a mother of three small children, moralities of care and cleanliness were more important than saving resources or the environment. The practicalities of cooking for children who don't want to eat the food she puts on the table, and coping with a child with behavioural problems matters more to her than dealing with recycling. Yet the removal of the cardboard collection meant there was no way for her to avoid engaging with the moral economy of recycling because of the limited capacity within her bin. Ivy is 'forced to recycle' much of their household waste and has had to find a way to get rid of the cardboard despite her rejection of the moral imperative to recycle.

Brian and Ivy have joined with neighbours to get rid of their cardboard, taking it in turns to burn the waste in their gardens. Whilst less organised than the 'Cardboard Christmas' campaign, we see elements of this collective community spirit in these communal burning actions. For Brian, this practice is viewed as a waste of valuable resources, whereas for Ivy, the loss of grass in her garden where she plays with her children is a reminder that the things that matter to her are not recognised by policy makers at the level of state regulation.

By exploring how these lay normativities are negotiated in the context of broader changes to systems of recycling provision, we learn how consumers own moral evaluations intersect 
with and sometimes run up against those moral agendas and policies pursued by the state and other organisations. Consumers are quite capable of giving reasoned justifications for their participation within recycling schemes and these may not reflect the environmental moralities and economies of worth that shape macro or meso level practices. By listening to consumer voices at the micro-level, we can explore how they respond to the various attempts by different organisations to govern their everyday practices according to a particular vision of morality. We can see how the material infrastructures and economic policies devised to protect the environment both enable and constrain opportunities for moral practices on the everyday level. We learn how societal critiques of wasteful consumption and environmental damage are either appropriated or rejected by consumers who negotiate and adapt the relevance of these critiques for their own local situations.

\section{DISCUSSION}

This case of ceased cardboard collection in Shropshire offers insights into the usefulness of the moral economy framework. Whilst much research has explored either the role of the state and institutions in the governance of recycling schemes (Davies, 2008; Gille, 2007) or the everyday practices of consumers (Evans, 2014; Gregson et al., 2007), bringing these layers of analysis together in tandem with broader societal critiques of rising levels of consumer waste and debates about how it should best be handled (Girling, 2005; Simms et al., 2009), offers a critical, relational account of the constitution of the moral economy of recycling. 
This example was used to show the importance of exploring the moral economy through a multi-layered framework, constituted in a distinct instituted system of provision that is emplaced and subject to change over time. Each layer adds an important element to the analysis which if viewed in isolation would give a skewed view of how morals are constituted in markets. If we were to just focus on state regulation and neo-liberal changes to recycling policies, we would miss how these policies were influenced by environmental, organisational and community groups whose different interests have on the one hand provided the impetus for these policies to be enforced, and on the other resisted the consequences of such changes through the creation of alternative markets for recyclable materials. We would also miss the differential impact of such regulatory shifts on consumers from different socio-demographic backgrounds whose everyday moralities of care and cleanliness might be threatened by these shifts and so challenge the legitimacy/success of state intervention. If we only focus on how different organisations moralise the market through critical discourses and actions that defend their 'collective customs', we miss how ideas about recycling and environmental protection have already become embedded within legislative and political regimes and how these are transforming understanding of market morality, as well as how everyday strategies for handling problematic waste might shape how these community organisations and critical narratives are able to develop new markets. If we only concentrate on the feelings of commitment and apathy towards recycling on an individual level, we miss how the cultural repertoires 
that connect recycling with worthiness have been worked upon by a range of institutions, and how the material infrastructures provided through state and private sector provision are constraining and enabling the enactment of valued practices. Finally, emplacing these three layers within an instituted system of provision is crucial if we are to understand the contingent and shifting place of the moral economy. The changes to national composting certification had different repercussions in different parts of England because they interacted with already-embedded institutional configurations of material infrastructure, collection systems and divisions of labour between public/private sectors. The moral economy is not fixed in time but constantly evolving; for example, the public outcry against the cessation of cardboard recycling has eventually led to a return of the collection service in 2016, though not without much negotiation between Veolia, the council and residents about the value of such a change. Opportunities and constraints are realized in the dynamic interactions between these layers of analysis and possibilities are opened for new moralities and identities to be performed, as well as new systems of provision to be created.

\section{CONCLUSION}

This paper has made a case for bringing together longstanding normative critiques of consumption with more relational or agnostic accounts of the constitution of morality within the market. It is argued such an approach is necessary to move us beyond models of the moral economy that rely on the enduring analytical separation between the worlds of 
rational economic activity and relations of sentiment and solidarity. Morals and markets are better explored as continually negotiated social and political projects that are shaped by various forces, including academic and societal critique of consumption, institutional frameworks, cultural conventions and everyday reflections of consumers. Bringing these diverse literatures together into an overarching frame is important because it allows us to hold onto a critical stance on the morality of consumption practices at the same time as we explore how the meanings of these moralities are configured in distinct socio-historical contexts. It also draws our attention to the different levels at which mobilisation of consumer moralities might effectively transform the market towards more sustainable consumption practices - be that state regulation, community activism, academic critique or everyday reflection - and how the interactions between these levels that might enable or constrain such transformations.

The framework developed in this paper is designed to be attentive to the ways moralities of consumption develop through a process of continuous negotiation at the macro, meso and micro levels. Any attempt to study moral economies must pay attention to all three layers of this analytical framework, configured within an instituted system of provision. Failure to do so is likely to lead, on the one hand, to a thick descriptive account of the configuration of state/institutional responsibilities that details how political-economic structures are formed and reproduced, yet ignores how these structures are experienced by and shaped within communities of consumers who have moral projects of their own. On the other 
hand, just focusing on the ways that consumers use goods to enact their relationships of care and communicate their values will ignore how the possibilities for them to act 'responsibly' and contribute to a moral economy are shaped by political-economic structures and forms of state regulation that may or may not align with their lay normativities. By exploring the interactions between and within these levels - the interplay, the challenges and the acceptance - we can gain greater understanding of the place of morality within the economy.

\section{FUNDING ACKNOWLEDGEMENT}

The research on recycling was funded by an ERC Advanced Investigator Grant, led by Professor Miriam Glucksmann: 'Consumption Work and Societal Divisions of Labour' (DivLab 249430).

\section{ACKNOWLEDGEMENTS}

The author would like to thank Professor Miriam Glucksmann for her comments on this framework and for being such a valued mentor and friend. I would also like to extend my heartfelt thanks to the two anonymous reviewers who provided such detailed, thoughtful and constructive feedback on my paper. Their insights significantly improved the framework and I am very grateful to them for the time they evidently took to prepare their reports. 


\section{NOTES}

${ }^{1}$ The research was undertaken in 2011-2013 for the research programme 'Consumption Work and Societal Divisions of Labour' . This project explored practices of recycling in Sweden and England.

${ }^{2}$ This approach is similar to that adopted by Messner (2000) to show the merits of a specific theoretical model using individual empirical incidents.

\section{REFERENCES}

Ariztía T, Kleine D, Brightwell M, et al. (2014) Ethical consumption in Brazil and Chile: Institutional contexts and development trajectories. Journal of Cleaner Production 63: 8492.

Bandelj N (2012) Relational Work and Economic Sociology. Politics \& Society 40(2): 175201.

Barnett C, Cloke P, Clarke N, et al. (2011) Globalizing Responsibility. Oxford: WileyBlackwell.

Block F and Polanyi K (2003) Karl Polanyi and the Writing of ‘The Great Transformation'. Theory and Society 32(3): 275-306.

Boltanski L and Thévenot L (1999) The Sociology of Critical Capacity. European Journal of Social Theory 2(3): 359-377. 
Bolton SC and Laaser K (2013) Work, employment and society through the lens of moral economy. Work, Employment \& Society 27(3): 508-525.

Boström M and Klintman M (2006) State-centered versus nonstate-driven organic food standardization: A comparison of the US and Sweden. Agriculture and Human Values 23(2): 163-180.

Brown K (2013) Buying into Fair Trade. New York: NYU Press.

Callon M (1998) The laws of the markets. Introduction: The embeddednes of economic markets in economics. The Sociological Review 46(S1): 1-58.

Callon M, Millo Y and Muniesa F (eds) (2007) Market Devices. Oxford: Blackwell Publishing. Cohen L (2003) A Consumers' Republic. New York: Alfred A. Knopf.

Davies A (2008) The Geographies of Grabage governance. Hampshire: Ashgate.

DEFRA (2011) Government Review of W aste Policy in England 2011. Government Waste Policy Review, London.

Evans D (2014) Food waste. London: Bloomsbury.

FOE (2004) Biowaste: towards a Friends of the Earth position. Available from: https://www.foe.co.uk/sites/default/files/downloads/biowaste_guide.pdf.

Fourcade M and Healy K (2007) Moral Views of Market Society. Annual Review of Sociology 33(1): 285-311.

Fridell G (2006) Fair trade and the international moral economy: Within and against the market. In: Shallcross T and Robinson J (eds), Global Citizenship and Environmental Justice, Atlanta: Rodopi, pp. 81-94. 
Gille Z (2007) The politics of waste in socialist and postsocialist Hungary. Bloomington: Indiana University Press.

Girling R (2005) Rubbish! Dirt on our hands and crises abead. London: Transworld Publishers.

Goodman MK (2004) Reading fair trade: Political ecological imaginary and the moral economy of fair trade foods. Political Geography 23(7): 891-915.

Granovetter M (1985) Economic action and social structure: the problem of embeddedness. American journal of sociology 91(3): 481-510.

Gregson N, Metcalfe A and Crewe L (2007) Identity, mobility, and the throwaway society. Environment and Planning D: Society and Space 25(4): 682-700.

Harvey M (2007) Instituting economic processes in society. In: Harvey M, Ramlogan R, and Randles S (eds), Karl Polanyi: New perspectives on the place of economy in society, Manchester: Manchester University Press, pp. 163-184.

Jackson P, Ward N and Russell P (2009) Moral economies of food and geographies of responsibility. Transactions of the Institute of British Geographers 34(1): 12-24.

King S (2008) Pink Ribbons, Inc.: Breast Cancer and the Politics of Philanthropy. Minneapolis: University of Minnesota Press.

Klein N (2000) No Logo. London: Harper Perennial.

Krippner GR (2001) The Elusive Market : Embeddedness and the Paradigm of Economic Sociology. Theory and Society 30(6): 775-810.

Mcfall L (2009) Devices and Desires: How Useful Is the 'New' New Economic Sociology for Understanding Market Attachment? Sociology Compass 3(2): 267-282. 
Messner M (2000) Barbie Girls Versus Sea Monsters: Children constructing gender. Gender \& Society 14(6): 765-784.

Miller D (2001) The poverty of morality. Journal of Consumer Culture 1(2): 225-243.

Packard V (1960) The Waste Makers. London: Longmans.

Pellandini-Simányi L (2014) Consumption Norms and Everyday Ethics. Hampshire: Palgrave Macmillan.

Polanyi K (1944) The Great Transformation. Massachusetts: Beacon Press.

Polanyi K (1957) The Economy as Instituted Process. In: Polanyi K, Arensberg C, and Pearson H (eds), Trade and Market in the Early Empires, Illinois: The Free Press, pp. 243-269.

Sayer A (2000) Moral Economy and Political Economy. Studies in Political Economy 61: 79_ 103.

Sayer A (2005) The Moral Significance of Class. Cambridge: Cambridge University Press.

Sayer A (2011) Why things matter to people: Social science, V alues and Ethical Life. Cambridge: Cambridge University Press.

Schor JB, Slater D, Zukin S, et al. (2010) Critical and Moral Stances in Consumer Studies. Journal of Consumer Culture 10(2): 274-291.

Simms A, Johnson V, Smith J, et al. (2009) The Consumption Explosion. London.

Soper K (2008) Alternative Hedonism, Cultural Theory and the Role of Aesthetic Revisioning. Cultural Studies 22(5): 567-587.

Szasz A (2009) Shopping our Way to Safety. Minneapolis: University of Minnesota Press. 
Thompson EP (1971) The Moral Economy of the English Crowd in the Eighteenth Century. Past and Present 50: 76-136.

Trentmann F (2007) Before 'fair trade': Empire, free trade, and the moral economies of food in the modern world. Environment and Planning D: Society and Space 25(6): 1079_ 1102.

Varul MZ (2009) Ethical selving in cultural contexts: fairtrade consumption as an everyday ethical practice in the UK and Germany. International Journal of Consumer Studies 33(2): 183-189.

Wheeler K (2012a) ‘Change Today, Choose Fairtrade’. Cultural Studies 26(4): 492-515.

Wheeler K (2012b) Fair Trade and the Citizen-Consumer: Shopping for Justice. Hampshire: Palgrave Macmillan.

Wheeler K (2014) Nice save: The moral economies of recycling in England and Sweden. Environment and Planning D: Society and Space 32(4): 704-720.

Wheeler K and Glucksmann M (2015) Household recycling and consumption work: social and moral economies. Hampshire: Palgrave Macmillan.

Zelizer VA (2011) Economic Lives: How culture shapes the economy. Princeton: Princeton University Press. 
